\title{
Post-stroke dysphagia: frequency, risk factors, and topographic representation: hospital-based study
}

\author{
Eman M. Khedr ${ }^{1,2^{*}}$ (D), Mohamed A. Abbass ${ }^{3}$, Radwa K. Soliman ${ }^{4}$, Ahmed F. Zaki ${ }^{5}$ and Ayman Gamea ${ }^{5}$
}

\begin{abstract}
Background: The frequency of dysphagia varies considerably across literature. Post-stroke dysphagia is a common cause of increased morbidity and length of hospitalization. This study aimed to estimate the frequency, risk factors of dysphagia following first-ever ischemic or hemorrhagic stroke and its neuroradiological correlation.

Methods: Two hundred fifty patients (180 ischemic and 70 hemorrhagic strokes) with first-ever stroke were recruited within $72 \mathrm{~h}$ of onset. Detailed history, neurological examination, and computed tomography and/or magnetic resonance were done for each patient. Severity of stroke was evaluated by the National Institutes of Health Stroke Scale (NIHSS). Swallowing function was assessed by water swallowing test (WST) and dysphagia outcome severity scale (DOSS).
\end{abstract}

Results: Ninety-eight (39.2\%) of all stroke patients had dysphagia, 57 (31.7\%) of ischemic group, 41 (58.6\%) of hemorrhagic group. The mean age of ischemic group with dysphagia was older than ages of non-dysphagic and older than hemorrhagic stroke with dysphagia group. The mean total NIHSS was higher in dysphagic group than non-dysphagic group in both ischemic and hemorrhagic stroke. Dysphagia in ischemic group was highly associated with diabetes mellitus (DM), hypertension (HTN), and atrial fibrillation (AF). Dysphagia was commonly associated with middle cerebral artery (MCA), brainstem, and capsular infarctions as well as with intracerebral hemorrhage $(\mathrm{ICH})$ with ventricular extension. Stroke severity and lesion size were the main determinant of dysphagia severity.

Conclusions: The frequency of post-stroke dysphagia is consistent with other studies. Advanced age, DM, HTN, and AF were the main risk factors. MCA, brain stem, capsular infarctions, and ICH with ventricular extension were frequently associated with dysphagia. Stroke severity and lesion size were independent predictors of dysphagia severity.

Keywords: Post-stroke dysphagia, Frequency, Water swallowing test, Dysphagia outcome severity scale

\section{Introduction}

Stroke is one of five leading causes of disability-adjusted life-years (DALYs) worldwide [1]. Prevalence of stroke in Upper Egypt has been estimated to be 9.62/1000 and 9.22/ 1000 in Assiut and Qena governorate respectively [2, 3]. Swallowing problems associated with stroke have been

\footnotetext{
* Correspondence: emankhedr99@yahoo.com

'Department of Neuropsychiatry, Assiut University Hospital, Assiut, Egypt ${ }^{2}$ Neuropsychiatric Department, Faculty of Medicine, Aswan University Hospital, Aswan, Egypt

Full list of author information is available at the end of the article
}

known as post-stroke dysphagia and it is one of the most feared complications of stroke as it occurs in $39-81 \%$ of stroke patients $[4,5]$. Post-stroke dysphagia is a common cause of morbidity including dehydration, aspiration pneumonia, and malnutrition, also causes prolonged hospitalization and increased mortality rate [6-8]. Early screening for post-stroke dysphagia reduces aspiration pneumonia after stroke and improves stroke outcome [9]; therefore, early detection and timely intervention for poststroke dysphagia could be considered an essential part of acute management of stroke. Studies address post-stroke

\section{Springer Open}

(ㅇ The Author(s). 2021 Open Access This article is licensed under a Creative Commons Attribution 4.0 International License, which permits use, sharing, adaptation, distribution and reproduction in any medium or format, as long as you give appropriate credit to the original author(s) and the source, provide a link to the Creative Commons licence, and indicate if changes were made. The images or other third party material in this article are included in the article's Creative Commons licence, unless indicated otherwise in a credit line to the material. If material is not included in the article's Creative Commons licence and your intended use is not permitted by statutory regulation or exceeds the permitted use, you will need to obtain permission directly from the copyright holder. To view a copy of this licence, visit http://creativecommons.org/licenses/by/4.0/. 
dysphagia and its risk factors are scarce in Egypt. The aim of this study is to evaluate the frequency and risk factors of dysphagia following first-ever ischemic or hemorrhagic stroke and its relation with neuroimaging.

\section{Methods}

The study was a cross-sectional study of all stroke patients admitted to the stroke unit of our hospital during the period from first of October 2015 to end of March 2016. Each patient presented by first-ever stroke with or without dysphagia within $72 \mathrm{~h}$ of onset and documented by computed tomography of the brain (CT) and/or magnetic resonance imaging (MRI) (ischemic infarction or hemorrhagic stroke) was included. Exclusion criteria were as follows: patients below 18 years old, disturbed conscious level, patients with transient ischemic attacks, and subarachnoid hemorrhage or venous sinus thrombosis. Patients in whom brain imaging showed previous or silent strokes were excluded. Patients with history of any swallowing disorders or any medical diseases affecting the swallowing process, patients with history of head injury or neurological disease other than stroke, and patients with mental retardation or any history of cognitive decline prior to stroke were excluded. Written informed consent was obtained from all patients; the study was approved by the local ethics committee.

\section{Clinical data collection}

Demographic data and clinical assessment after the establishment of stroke were recorded. A detailed history and neurological examination including bulbar muscle examinations as gag reflex and volitional cough response were performed for each participant. CT and/or MRI brain were done for each patient. The main cardiovascular risk factors (hypertension, diabetes, hyperlipidemia, smoking, atrial fibrillation, and ischemic heart diseases) were evaluated. The functional disability of each patient was assessed with the National Institutes of Health Stroke Scale (NIHSS) [10]. Stroke lesion size was calculated by measuring the maximum largest visible dimension as the widest anteroposterior multiplied by widest side to side diameter on CT or MRI scan [11] by the included Dicom viewer software (Toshiba Aquilion 64 CT scanner Japan, Philips-Achieva 1.5 Tesla MRI machine Netherlands) by the same radiologist who was blinded to the patients' data.

\section{Swallowing function assessment}

1) Clinical assessment of bulbar muscle function:

(a) Gag reflex-normal gag reflex response is considered when there is elevation of velum or posterior pharyngeal wall unilaterally or bilaterally to tactile stimulation, abnormal gag reflex is considered when the response is diminished or absent. (b) Voluntary cough response is the response of the patient to voluntary cough command, abnormal cough reflex is considered when there is no response, vocalized or weakened cough [12].

2) Water swallowing test (WST) - the presence or absence of dysphagia was assessed by WST by asking the patient to swallow $30 \mathrm{ml}$ of water at room temperature as usual and observes how many times he/she swallows and if he/she ever gets choked. It is considered positive if the patient could swallow at once without choking, coughing, or change in voice quality within $5 \mathrm{~s}$. The test was repeated twice for 2 consecutive days [13].

3) Dysphagia outcome severity scale (DOSS) - is a simple and easy to use seven levels scale built to determine the severity of dysphagia can recommend the level and dependency of feeding. Level 1 mounts to severe dysphasia as the patient cannot tolerate per oral intake, level 2 mounts to moderate-severe dysphagia as maximum assistance with partial per oral intake only, the patient can tolerate at least one consistency safely with maximum precautions. Level 3 mounts to moderate dysphagia as total supervision and two or more diet consistencies restricted. Level 4 mounts to mild-moderate dysphagia as intermittent supervision is needed and one or two consistencies restricted. Level 5 mounts to mild dysphagia as distant supervision needed and may need one diet consistency restricted. Level 6 mount to swallowing within functional limits/modified independence. Level 7 refers to swallowing that normal in all situations [14]. WST and DOSS were performed by a neurologist with at least 6 months of experience in assessment of dysphagia, blinded to data and clinical examination.

Dysphagia was diagnosed if there is abnormal gag reflex and volitional cough response in addition to abnormal water swallowing test.

\section{Statistical analysis}

The data were analyzed using the SPSS 16.0 software. Qualitative data were described in frequency using percentage (\%). Continuous variables were expressed in mean \pm standard deviation (SD). Comparative statistical analysis between variables was done using chi-square for qualitative data and independent $t$ test for continuous variables. A value of $P$ $<0.05$ was considered statistically significant. Correlation coefficients were calculated to assess the direction and magnitude of association between stroke 
lesion size and total NIHSS in relation to severity of dysphagia depending on the dysphagia outcome severity scale using Pearson's correlation. Multivariable regression analysis was performed to assess the predictors of severity of dysphagia.

\section{Results}

\section{Demographic data of all cases of stroke}

The study was carried on 250 patients presented with stroke. One hundred eighty were suffering from ischemic strokes and 70 hemorrhagic strokes. The mean \pm SD for patient's age was $54.6 \pm 11.3,122$ patients were males and 128 were females with no significant difference $(P$ value $=0.27)$. The mean age \pm SD for patients with ischemic stroke was $56.1 \pm 1.5$ and significantly higher than patients with hemorrhagic stroke (50.9 \pm 13.3) $(P=0.001)$. Ninety-eight $(39.2 \%)$ out of 250 patients had dysphagia. In ischemic stroke patients, 57 (31.7\%) had dysphagia while in hemorrhagic stroke patients, 41 (58.6\%) had dysphagia with non-significant difference ischemic versus hemorrhagic stroke.

The mean age \pm SD for patients with dysphagia in ischemic stroke was $58.3 \pm 8.5$ with significant difference compared with patients without dysphagia $(55.2 \pm 10.6)$ with $P=0.036$. There was no relation between dysphagia and sex distributions. (Table 1).

The mean total NIHSS \pm SD for patients with ischemic stroke with dysphagia was significantly higher $(13.6 \pm 6.1)$ than in patients without dysphagia ( $7.3 \pm 3.6$ with $P<0.0001)$.

According to the side of hemispheric affection in relation to dysphagia, there is a slight predominance of dysphagia with right-sided lesions (53.9\%) in comparison to the left hemispheric lesions with insignificant difference $\left(X^{2}=0.215, P=0.642\right)$.

The relation between risk factors in ischemic stroke with versus without dysphagia

There were significant differences between patients with dysphagia and patients without dysphagia in the risk factors of ischemic stroke. AF, DM, and HTN were significantly higher in dysphagic than non-dysphagic patients (Table 2).
The presence and the degree of dysphagia in ischemic stroke in relation to radiological site of lesion

The most common site of the lesion associated with dysphagia was MCA infarctions (28.1\%) followed by brain stem (21.1\%). Majority of cases with MCA, brain stem infarction, and capsular infarctions had associated with severe grade of dysphagia (Table 3 ).

\section{Demographic data of hemorrhagic stroke patients}

Forty-one patients out of 70 hemorrhagic stroke patients (58.6\%) had dysphagia. The mean age \pm SD $(49.8 \pm 13.3)$ for patients with dysphagia in hemorrhagic stroke showed no significant difference compared with patients without dysphagia $(51.1 \pm 13.4)(P=0.737)$. There was no association between sex and dysphagia in hemorrhagic stroke patients (Table 4).

In hemorrhagic stroke, the mean total NIHSS \pm SD $(13.8$ \pm 6 ) for patients with dysphagia was significantly higher than in patient without dysphagia $(6.1 \pm 2.5)(P<0.001)$.

\section{The relation between risk factors in hemorrhagic stroke (70 cases) with versus without dysphagia}

There were no significant differences between patients with dysphagia and patients without dysphagia in any of the risk factors associated with hemorrhagic stroke (Table 5).

\section{The presence and the degree of dysphagia in} hemorrhagic stroke in relation to radiological site of lesion

The most common site of the lesion associated with dysphagia was ICH with intraventricular extension (36.6\%). Most of the cases with $\mathrm{ICH}$ with intraventricular extension had severe grade of dysphagia. Details of each site of lesion are illustrated in Table 6.

\section{Correlation analysis results}

There was a significant negative correlation observed between DOSS score and stroke lesion size and total NIHS $\mathrm{S}(r=0.774, P=<0.0001$, and $r=0.580, P=<0.0001$ respectively). Figures 1 and 2 illustrate the significant correlations.

Table 1 Demographic data of all ischemic stroke patients

\begin{tabular}{lllll}
\hline Parameter & $\begin{array}{l}\text { Total number (180 } \\
\text { cases) }\end{array}$ & $\begin{array}{l}\text { Patients with } \\
\text { dysphagia, } \mathbf{N}=\mathbf{5 7}\end{array}$ & $\begin{array}{l}\text { Patients without } \\
\text { dysphagia, } \mathbf{N = 1 2 3}\end{array}$ & $\begin{array}{l}\boldsymbol{P} \text { value (Chi-square) between patients with or } \\
\text { without dysphagia }\end{array}$ \\
\hline $\begin{array}{l}\text { Age (mean } \pm \\
\text { SD) }\end{array}$ & $56.1 \pm 1.5$ & $58.3 \pm 8.55$ & $55.2 \pm 10.6$ & 0.036 \\
$\begin{array}{l}\text { Sex, male/ } \\
\text { female }\end{array}$ & $84 / 96$ & $26 / 31$ & $58 / 65$ & 0.847 \\
$\begin{array}{l}\text { Handedness } \\
\text { RT/LT }\end{array}$ & $172 / 8$ & $53 / 4$ & $119 / 4$ & 0.254
\end{tabular}


Table 2 Risk factor of ischemic stroke patients according to presence or absence of dysphagia

\begin{tabular}{lllll}
\hline Parameter & $\begin{array}{l}\text { Total number (180 cases), } \\
\boldsymbol{N} \text { (percent) }\end{array}$ & $\begin{array}{l}\text { Patients with dysphagia (57 } \\
\text { cases), } \boldsymbol{N} \text { (percent) }\end{array}$ & $\begin{array}{l}\text { Patients without dysphagia (123 } \\
\text { cases), } \boldsymbol{N} \text { (percent) }\end{array}$ & $\begin{array}{l}\boldsymbol{P} \text { value (Chi- } \\
\text { square) }\end{array}$ \\
\hline $\begin{array}{l}\text { Hypertension (HTN) } \\
\text { Diabetes mellitus }\end{array}$ & $53(28.8 \%)$ & $11(19.2 \%)$ & $41(33.3 \%)$ & 0.053 \\
(DM) & $24(42.1 \%)$ & $29(23.6 \%)$ & 0.011 \\
Smoking & $41(18.3 \%)$ & $12(21.1 \%)$ & $29(23.6 \%)$ & 0.707 \\
Obesity & $33(21.1 \%)$ & $13(22.9 \%)$ & $20(16.2 \%)$ & 0.291 \\
Dyslipidemia & $24(13.3 \%)$ & $10(17.5 \%)$ & $14(11.4 \%)$ & 0.258 \\
Substance abuse & $10(22.8 \%)$ & $4(7.01 \%)$ & $6(4.9 \%)$ & 0.56 \\
$\begin{array}{l}\text { Ischemic heart } \\
\text { disease (IHD) }\end{array}$ & $15(3.3 \%)$ & $7(12.2 \%)$ & $8(6.5 \%)$ & 0.192 \\
Hyperuricemia & $13(8.3 \%)$ & $2(3.5 \%)$ & $11(8.9 \%)$ & 0.190 \\
Atrial fibrillation (AF) & $19(10.6 \%)$ & $14(24.6 \%)$ & $5(4.06 \%)$ & $<0.0001$ \\
\hline
\end{tabular}

\section{Multivariable regression analysis results}

Age, sex, handedness, stroke lesion size, and total NIHS $\mathrm{S}$ were entered into simple linear regression analysis model using DOSS as a dependent variable. According to the model, all variables accounted for $67 \%$ of the variance of dysphagia severity $\left(f=33.216\right.$, adjusted $R^{2}=$ 0.666). Only stroke lesion size (beta weight $=0.651, t=$ 9.608 and $P<0.0001$ ) and total NIHSS (beta weight $=$ $0.201, t=2.305$, and $P=0.023$ ) were considered in the predicted direction for severity of dysphagia (Table 7).

\section{Discussion}

Dysphagia is one of the most common sequels of acute stroke, affecting as many as 50\% of acute stroke survivors. The presence of dysphagia in stroke survivors has been associated with increased mortality and morbidities such as pulmonary complications, malnutrition, and dehydration $[7,15]$.

In our study, we found that the frequency of dysphagia following acute stroke (ischemic and hemorrhagic strokes) was $39.2 \%$, which was

Table 3 Presence and degree of dysphagia (DOSS score) in ischemic stroke in correlation to radiological site of lesion

\begin{tabular}{|c|c|c|}
\hline Site of lesion & $\begin{array}{l}\text { Number of Cases of ischemic stroke with } \\
\text { dysphagia } \\
\text { Number (\%) }\end{array}$ & $\begin{array}{l}\text { Number and degree of } \\
\text { dysphagia } \\
\text { (dysphagia outcome severity } \\
\text { scale) }\end{array}$ \\
\hline Parietal infarction & $3(5.3 \%)$ & 3 cases (mild degree) \\
\hline $\begin{array}{l}\text { Parietal-occipital infarction extend to cuneus and precuneus } \\
\text { areas }\end{array}$ & $2(3.5 \%)$ & 2 cases (moderate degree) \\
\hline Capsular & $6(10.6 \%)$ & $\begin{array}{l}3 \text { cases (severe degree) } \\
2 \text { cases (moderate degree) } \\
1 \text { case (mild degree) }\end{array}$ \\
\hline frontal-operculum infarction & $4(7 \%)$ & $\begin{array}{l}2 \text { cases (mild degree) } \\
2 \text { cases (moderate degree) }\end{array}$ \\
\hline Basal ganglionic infarction & $4(7 \%)$ & $\begin{array}{l}2 \text { cases (mild degree) } \\
2 \text { cases (moderate degree) }\end{array}$ \\
\hline Thalamic infarction & $3(5.3 \%)$ & 3 cases (mild degree) \\
\hline Brain stem infarction & $12(21.1 \%)$ & \\
\hline Midbrain & 2 & 4 cases (moderate degree) \\
\hline Pons & 4 & 2 cases (mild degree) \\
\hline Medulla & 6 & 6 cases (severe degree) \\
\hline Cerebellar infarction & $1(1.8 \%)$ & 1 case (moderate degree) \\
\hline Fronto-parietal operculum & $6(10.6 \%)$ & $\begin{array}{l}2 \text { cases (mild degree) } \\
4 \text { cases (moderate degree) }\end{array}$ \\
\hline Complete MCA occlusion & $16(28.1 \%)$ & $\begin{array}{l}12 \text { cases (severe degree) } \\
4 \text { cases (moderate degree) }\end{array}$ \\
\hline
\end{tabular}


Table 4 Demographic data of all hemorrhagic stroke patients

\begin{tabular}{|c|c|c|c|c|}
\hline Parameter & $\begin{array}{l}\text { Total number of cases, } N= \\
70\end{array}$ & $\begin{array}{l}\text { Patients with dysphagia, } N= \\
41\end{array}$ & $\begin{array}{l}\text { Patients without dysphagia, } N= \\
29\end{array}$ & $\begin{array}{l}P \text { value (Chi- } \\
\text { square) }\end{array}$ \\
\hline Age (mean $\pm S D)$ & $50.4 \pm 13.3$ & $49.8 \pm 13.3$ & $51.1 \pm 13.4$ & 0.737 \\
\hline Sex, male/female & $32 / 38$ & $22 / 19$ & $16 / 13$ & 0.900 \\
\hline $\begin{array}{l}\text { Handedness, RT/ } \\
\text { LT }\end{array}$ & $65 / 5$ & $38 / 3$ & $27 / 2$ & 0.946 \\
\hline
\end{tabular}

$S D \pm$ standard deviation, $R T$ right, $L T$ left

consistent with Martino and colleagues [4] who found the frequency ranging from between 29 and 67\%. In Egypt, El-Sheikh [16] reported that dysphagia occurred in $45 \%$ of both types of strokes.

In the present study, dysphagia frequency in ischemic stroke cases was $31.7 \%$. This in line with many studies as the frequency of dysphagia in ischemic strokes was $40 \%$ by Suntrup and colleagues [17] and $20-50 \%$ by Arnold and colleagues [7].

In the current study, the frequency of dysphagia in hemorrhagic strokes was $58.6 \%$. This percentage is nearly similar to many studies as in Egypt 72\% [16] and in India $67 \%$ [18]. This discrepancy in the frequency across literature may be attributed to differences in definition, time, tools of swallowing examinations, and patient selection.

The higher mean age of dysphagic patients in ischemic and hemorrhagic stroke than non-dysphagic patients was consistent with Remesso and colleagues [19] as they studied 596 patients with first-ever stroke and found a similar observation. It may be attributed to reduction in muscle tone, loss of elasticity of connective tissue, decreased saliva production, changes in sensory function, and decreased sensitivity of the mucosa [4].

In our study, the absence of gender effect on dysphagia was consistent with most of other studies which did not consider the gender as a risk factor for post-stroke dysphagia [20].
In the present study, DM and HTN were significantly associated with dysphagia in ischemic patients. This may be related to the superadded neuropathic element of DM which increases the morbidity of stroke [21]. The results of the present study agreed with previous studies $[22,23]$ as they reported that hypertension had poor prognostic influence on stroke manifestations, disabilities, and deficits after stroke. In the current study, AF is associated with dysphagia in ischemic stroke rather than nondysphagic patients. AF is long lasting considered a major risk factor of stroke and highly associated with severe stroke disability and morbidity in stroke survivors [24, 25].

Our findings suggest that dysphagia could occur with unilateral stroke either right or left hemispheric lesions with a slight predominance of the right-sided lesions. Transcranial magnetic stimulation studies confirm the interhemispheric asymmetry in cortical representation of swallowing as dysphagia could occur if the largest projection is affected while the pharynx is affected with right-sided lesions [26, 27].

In the current study, the stroke severity and lesion size were significantly correlated with severity of dysphagia in both types of stroke and considered as independent predictors of dysphagia. Mann and colleagues [28] proved that the disabling stroke are independent predictor for development of dysphagia. Murray and colleagues [29] proved that the overall functional

Table 5 Risk factor of hemorrhagic stroke patients according to presence or absence of dysphagia

\begin{tabular}{lllll}
\hline & $\begin{array}{l}\text { Total number of cases (70 } \\
\text { cases), } \boldsymbol{N} \text { (percent) }\end{array}$ & $\begin{array}{l}\text { Patients with dysphagia } \\
\text { (41cases), } \boldsymbol{N} \text { (percent) }\end{array}$ & $\begin{array}{l}\text { Patients without dysphagia (29 } \\
\text { cases), } \boldsymbol{N} \text { (percent) }\end{array}$ & $\begin{array}{l}\boldsymbol{P} \text { value (Chi- } \\
\text { square) }\end{array}$ \\
\hline $\begin{array}{l}\text { Hypertension (HTN) } \\
\text { Diabetes mellitus }\end{array}$ & $46(65.7 \%)$ & $27(65.9 \%)$ & $19(65.5 \%)$ & 0.977 \\
(DM) & $23(2.9 \%)$ & $13(31.8 \%)$ & $10(34.4 \%)$ & 0.808 \\
Smoking & $10(14.3 \%)$ & $4(9.8 \%)$ & $6(20.7 \%)$ & 0.198 \\
Obesity & $16(22.9 \%)$ & $10(31.7 \%)$ & $6(10.3 \%)$ & 0.716 \\
$\begin{array}{l}\text { Dyslipidemia } \\
\text { Substance abuse }\end{array}$ & $12(17.1 \%)$ & $9(21.9 \%)$ & $3(10.3 \%)$ & 0.204 \\
$\begin{array}{l}\text { Ischemic heart } \\
\text { disease (IHD) }\end{array}$ & $3(4.2 \%)$ & $8(19.5 \%)$ & $5(17.2 \%)$ & 0.810 \\
Hyperuricemia & $5(7.1 \%)$ & $1(2.4 \%)$ & $2(6.9 \%)$ & 0.397 \\
$\begin{array}{l}\text { Atrial fibrillation } \\
\text { (AF) }\end{array}$ & $1(1.4 \%)$ & $2(4.9 \%)$ & $3(10.3 \%)$ & 0.382 \\
\hline
\end{tabular}


Table 6 The presence and the degree of dysphagia (DOSS score) in hemorrhagic stroke in correlation to radiological site of lesion

\begin{tabular}{lll}
\hline Site of lesion & $\begin{array}{l}\text { Number of hemorrhagic stroke cases with } \\
\text { dysphagia (\%) }\end{array}$ & $\begin{array}{l}\text { Number and degree of dysphagia (dysphagia } \\
\text { outcome severity scale) }\end{array}$ \\
\hline $\begin{array}{l}\text { Temporal-parietal ICH } \\
\text { Frontal ICH }\end{array}$ & $2(4.9 \%)$ & $\begin{array}{l}\text { cases (moderate degree) } \\
1 \text { case (mild degree) } \\
1 \text { case (moderate degree) }\end{array}$ \\
$\begin{array}{ll}\text { Basal ganglionic ICH } \\
4(17.1 \%)\end{array}$ & $\begin{array}{l}4 \text { insular (moderate degree) } \\
\text { and others (mild degree) }\end{array}$ \\
$\begin{array}{l}\text { LT thalamic ICH } \\
\text { Inter ventricular ICH }\end{array}$ & $2(12.2 \%)$ & 2 cases (mild degree) \\
$\begin{array}{l}\text { Brain stem ICH } \\
\text { ICH with intraventricular extension }\end{array}$ & $5(12.2 \%)$ & 2 cases (mild degree) \\
$\begin{array}{l}6 \text { cases fronto-parietal with interventricular } \\
\text { extension }\end{array}$ & $15(36.6 \%)$ & 4 cases (severe degree) \\
$\begin{array}{l}6 \text { cases large basal ganglionic with } \\
\text { interventricular extension }\end{array}$ & & 1 case (moderate degree) \\
$\begin{array}{l}3 \text { cases thalamic with interventricular } \\
\text { extension }\end{array}$ & & 10 cases (severe degree) \\
Fronto-parietal ICH & $3(7.3 \%)$ & 3 cases (moderate degree) \\
\hline
\end{tabular}

$\mathrm{ICH}$ intracerebral hemorrhage

dependency was the most significant predictor for poor oral intake and fluid-related health outcomes of stroke. Rofes and colleagues [30] recorded that stroke severity with high NIHSS is a predictor of the development of dysphagia.

Our results were consistent with Toscano and colleagues as the lesion size considered as an independent predictor in persistent post-stroke dysphagia [31]

The current study showed an association between location of stroke and degree of dysphagia as patients with total MCA, brainstem infarction, and capsular infarctions had a higher degree of dysphagia. This may be attributed to involvement of important areas for swallowing in MCA lesions like the anterior cingulate gyrus, anterior insula, and portions of the post and

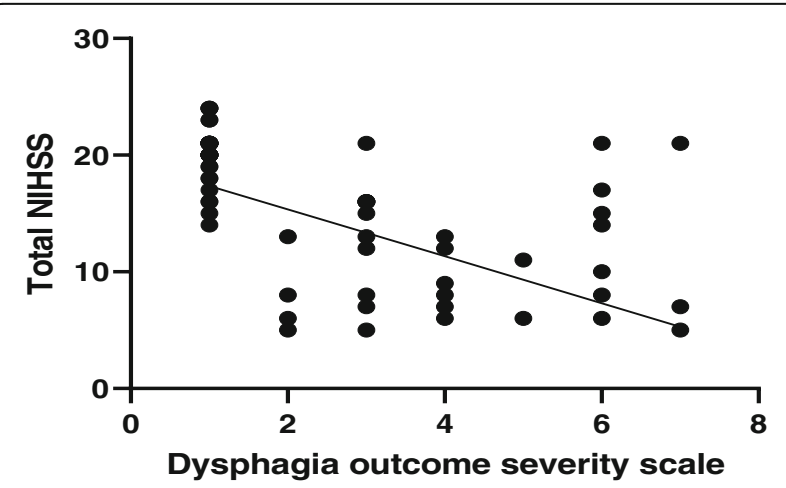

Fig. 1 Correlation between dysphagia outcome severity scale and total National Institutes of Health Stroke Scale, significant negative correlation between severity of dysphagia and NIHSS, $r=0.580, P$ $<0.0001$ precentral gyri [32]. In addition to high NIHSS associated with MCA infarction and brainstem lesions. Brain stem lesions causing dysphagia due to affection of the swallowing center located at the medulla [33]. In the present study, the high incidence of capsular infarction associated with dysphagia may be due to frequent involvement of swallowing corticobulbar projections [34, 35]. The current study showed that frontoparietal operculum and parietal infarctions were associated with dysphagia which may be due to involvement of primary somatosensory, motor, and supplementary areas involving in motor regulation and sensory control of swallowing in addition to insular processing of gustatory input [36]. We observed an association of dysphagia with parietooccipital lesions which may be due to impairment in

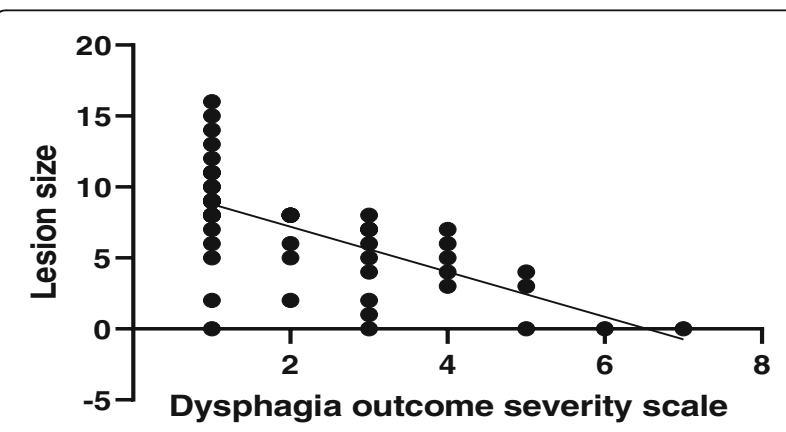

Fig. 2 Correlation between dysphagia outcome severity scale and lesion size, significant negative correlation between severity of dysphagia and stroke size, $r=0.774, P<0.0001$ 
Table 7 Multivariable regression analysis for severity of dysphagia

\begin{tabular}{lllll}
\hline Model & $\boldsymbol{B}$ & $\boldsymbol{B e t a}$ & $\boldsymbol{t}$ & $\boldsymbol{P}$ \\
\hline (Constant) & 4.071 & & 3.583 & 0.001 \\
Age & 0.011 & 0.073 & 1.175 & 0.243 \\
Sex & -0.395 & -0.113 & -1.916 & 0.059 \\
Handedness & 0.469 & 0.069 & 1.156 & 0.251 \\
Lesion size (maximum dimension) & -0.318 & -0.651 & -9.608 & 0.000 \\
Total NIHSS & -0.058 & -0.201 & -2.305 & 0.023 \\
\hline
\end{tabular}

Dependent variable: dysphagia outcome severity scale NIHSS National Institutes of Health Stroke Scale

sensory processing and movement planning of swallowing [37]. Suzuki and colleagues [38] found activation of basal ganglia during volitional swallowing by functional MRI and attributed basal ganglionic dysphagia due to lost sensory gating input of swallowing.

The high frequent association of dysphagia with thalamic lesions recorded in the present study may be due to loss of abundant connection to reticular activating system via ventro-postero-medialis nucleus of thalamus and destruction of thalamocortical and thalamostriatal pathways while dysphagia with cerebellar lesions may be due to dysregulation of coordination, timing, and sequencing of swallowing movements [39-41].

In hemorrhagic stroke, we thought that the higher frequency (36.6\%) and higher degree of dysphagia severity in patients with $\mathrm{ICH}$ and interventricular extension compared to other sites was due to higher NIHSS.

\section{Limitations}

The main limitations of this study were small sample size and not using an invasive objective test for detecting dysphagia like laryngoscope.

\section{Conclusions}

Post-stroke dysphagia is a common disorder needing vigilant assessment. Hemorrhagic strokes are more frequently associated with dysphagia than ischemic lesions. Older age, DM, HTN, and AF were the main risk factors for dysphagia occurrence. Stroke severity and stroke location are the main predictors for dysphagia while stroke severity and lesion size are the main predictors of dysphagia severity.

\section{Abbreviations}

AF: Atrial fibrillation; CT: Computed tomography; DM: Diabetes mellitus; DOSS: Dysphagia outcome severity scale; HTN: Hypertension; $\mathrm{ICH}$ : Intracerebral hemorrhage; IHD: Ischemic heart disease; MCA: Middle cerebral artery; MRI: Magnetic resonance imaging; NIHSS: National Institutes of Health Stroke Scale; WST: Water swallowing test

\section{Authors' contributions}

EMK, MA, RS, AF, and AG contributed to study concept and design acquisition of data, draft and revision of the report, statistical analyses, and interpretation of data. AFZ, MA, and AG contributed to case recruitments, acquisition of data, and statistical analyses. EMK, AFZ, and AG contributed to the editing of this report. All authors read and approved the final manuscript.

\section{Funding}

Not applicable.

\section{Availability of data and materials}

The datasets used and/or analyzed during the current study are available from the corresponding author reasonable on request.

Ethics approval and consent to participate

An informed consent was obtained from all the patients before participating in the study. The protocol was approved in January 2015 by the South Valley Medical School Ethical Review Board and all participants or relatives gave written informed consent before participation in the study. The ethical approval reference number was not applicable at the time of approval of the study. The confidentiality of the patients' information was maintained during all the steps of the study.

\section{Consent for publication}

Not applicable.

\section{Competing interests}

The authors declare that they have no competing interests.

\section{Author details}

${ }^{1}$ Department of Neuropsychiatry, Assiut University Hospital, Assiut, Egypt. ${ }^{2}$ Neuropsychiatric Department, Faculty of Medicine, Aswan University Hospital, Aswan, Egypt. ${ }^{3}$ Department of Neuropsychiatry, Luxor University, Luxor, Egypt. ${ }^{4}$ Department of Diagnostic and Interventional Radiology, Assiut University Hospital, Assiut, Egypt. ${ }^{5}$ Department of Neuropsychiatry, South Valley University Hospital, Qena, Egypt.

Received: 25 November 2020 Accepted: 27 January 2021 Published online: 10 February 2021

\section{References}

1. GBD 2017 DALYs and HALE Collaborators. Global, regional, and national disability adjusted life-years (DALYs) for 359 diseases and injuries and healthy life expectancy (HALE) for 195 countries and territories, 1990-2017: a systematic analysis for the Global Burden of Disease Study 2017. Lancet. 2018;392:1859-922.

2. Khedr EM, Elfetoh NA, Al Attar G, Ahmed MA, Ali AM, Hamdy A, et al. Epidemiological study and risk factors of stroke in Assiut Governorate, Egypt: community-based study. Neuroepidemiology. 2013;40(4):288-94.

3. Khedr EM, Fawi G, Abdela M, Mohammed TA, Ahmed MA, El-Fetoh NA, Zaki AF. Prevalence of ischemic and hemorrhagic strokes in Qena Governorate, Egypt: community-based study. J Stroke Cerebrovasc Dis. 2014;23(7):1843-8.

4. Martino R, Foley N, Bhogal S, Diamant N, Speechley M, Teasell R. Dysphagia after stroke: incidence, diagnosis, and pulmonary complications. Stroke. 2005;36:2756-63.

5. Steinhagen V, Grossmann A, Benecke R, Walter U. Swallowing disturbance pattern relates to brain lesion location in acute stroke patients. Stroke. 2009; 40:1903-6.

6. Crary MA, Humphrey JL, Carnaby-Mann G, Sambandam R, Miller L, Silliman S. Dysphagia, nutrition, and hydration in ischemic stroke patients at admission and discharge from acute care. Dysphagia. 2013;28:69-76.

7. Arnold M, Liesirova K, Broeg-Morvay A, Meisterernst J, Schlager M, Mono $\mathrm{ML}$, et al. Dysphagia in acute stroke: incidence, burden and impact on clinical outcome. PLoS One. 2016;11:e0148424.

8. Nguyen VQ, PrvuBettger J, Guerrier T, Hirsch MA, Thomas JG, Pugh TM, Rhoads CF 3rd. Factors associated with discharge to home versus discharge to institutional care after inpatient stroke rehabilitation. Arch Phys Med Rehabil. 2015;96:1297-303. 
9. Hinchey JA, Shephard T, Furie K, Smith D, Wang D. Tonn S; Stroke Practice Improvement Network Investigators: formal dysphagia screening protocols prevent pneumonia. Stroke. 2005;36:1972-6.

10. Brott T, Adams HP Jr, Olinger CP, Arler JR, Barsan WG, Biller J, et al Measurements of acute cerebral infarction: a clinical examination scale. Stroke. 1989:20:864-70.

11. Reith J, Jørgensen S, Pedersen PM, Nakayama H, Raaschou HO, Jeppesen LL, Olsen TS. Body temperature in acute stroke: relation to stroke severity, infarct size, mortality, and outcome. Lancet. 1996;347:422-5.

12. Bours GJ, Speyer R, Lemmens J, Limburg M, De Wit R. Bedside screening tests vs. videofluoroscopy or fibreoptic endoscopic evaluation of swallowing to detect dysphagia in patients with neurological disorders: systematic review. J Adv Nurs:65(3):477-93

13. Kubota T, Mishima H, Hanada M, Namba I, Kojima Y. Paralytic dysphagia in cerebrovascular disorder-screening tests and their clinical application. Sogo Rehabil. 1982;10:271-8 Japanese.

14. O'Neil KH, Purdy M, Falk J, Gallo L. The dysphagia outcome and severity scale. Dysphagia. 1999;14:139-45.

15. Smithard DG, Smeeton NC, Wolfe CDA. Long-term outcome after stroke: does dysphagia matter? Age Ageing. 2007;36:90-4.

16. El-Sheikh WM. Post-stroke dysphagia: incidence, diagnosis and complications. Egypt J Neurol Psychiat Neurosurg. 2010;47(1):175-83.

17. Suntrup S, Kemmling A, Warnecke T, Hamacher C, Oelenberg S, Niederstadt $\mathrm{T}$, et al. The impact of lesion location on dysphagia incidence, pattern and complications in acute stroke. Part 1: dysphagia incidence, severity and aspiration. Eur J Neurol. 2015;22(5):832-8.

18. Sundar U, Vimal P, Nishant D, Murar Y. Dysphagia in acute stroke: correlation with stroke subtype, vascular territory and in-hospital respiratory morbidity and mortality. Neurol India. 2008;56(4):436-70.

19. Remesso G, Fukujima M, Chiappetta A, Oda A, Aguiar A, Oliveira A, Prado G. Swallowing disorders after ischemic stroke. Arq Neuropsiquiatr. 2011;69(5): 785-9.

20. Gordon C, Hewer RL, Wade DT. Dysphagia in acute stroke. Br Med J (Clin Res Ed). 1987:295(6595):411-4.

21. American Diabetes Association. Standards of medical care in diabetes. Diabetes Care. 2012:S1-E113.

22. Lawes $C M$, Bennett DA, Feigin VL, Rodgers A. Blood pressure and stroke: an overview of published reviews. Stroke. 2004;35(3):776-85.

23. Willmot M, Leonardi-Bee J, Bath PM. High blood pressure in acute stroke and subsequent outcome: a systematic review. Hypertension. 2004;43(1):18-24.

24. Lin $\mathrm{H}-J$, Wolf PA, Kelly-Hayes M, Beiser AS, Kase CS, Benjamin EJ, et al. Stroke severity in atrial fibrillation. Stroke. 1996;27(10):1760-4 Ovid Technologies (Wolters Kluwer Health).

25. Wolf PA, Abbott RD, Kannel WB. Atrial fibrillation: a major contributor to stroke in the elderly. The Framingham Study. Arch Intern Med. 1987;147: 1561-4.

26. Robbins J, Levine RL, Maser A, Rosenbek JC, Kempster GB. Swallowing after unilateral stroke of the cerebral cortex. Arch Phys Med Rehabil. 1993;74(12): 1295-300.

27. Hamdy S, Rothwell JC, Aziz Q, Thompson DG. Organization and reorganization of human swallowing motor cortex: implications for recovery after stroke. Clin Neurosci. 2000;99(2):151-7.

28. Mann G, Hankey GJ, Cameron D. Swallowing function after stroke. Stroke. 1999;30(4):744-8 Ovid Technologies (Wolters Kluwer Health).

29. Murray J, Scholten I, Doeltgen S. Factors contributing to hydration, fluid intake and health status of inpatients with and without dysphagia post stroke. Dysphagia. 2018;33(5):670-83.

30. Rofes L, Muriana D, Palomeras E, Vilardell N, Palomera E, Alvarez-Berdugo D, Casado V, Clavé P. Prevalence, risk factors and complications of oropharyngeal dysphagia in stroke patients: a cohort study. Neurogastroenterol and Motil. 2018;30(8):e13338.

31. Toscano M, Cecconi E, Capiluppi E, Vigano A, Bertora P, Campiglio L, et al. Neuroanatomical, clinical and cognitive correlates of post-stroke dysphagia. Eur Neurol. 2015;74(3-4):171-7.

32. Malandraki G, Sutton B, Perlman A, Karampinos D, Conway C. Neural activation of swallowing and swallowing-related tasks in healthy young adults: an attempt to separate the components of deglutition. Hum Brain. 2009;30(10):3209-26.

33. Jean A. Brain stem control of swallowing: neuronal network and cellular mechanisms. Physiol Rev. 2001;81:929-69.
34. Monique G, Stephanie K, David M, Lisa C, Maryellen R, Anne L. Relevance of subcortical stroke in dysphagia. Stroke. 2010;41:482-6.

35. Mosier K, Patel R, Liu WC, Kalnin A, Maldjian J, Baredes S. Cortical representation of swallowing in normal adults: functional implications. Laryngoscope. 1999;109:1417-23.

36. Hamdy S, Mikulis DJ, Crawley A, Xue S, Lau H, Henry S, Diamant NE. Cortical activation during human volitional swallowing: an event-related fMRI study. Am J Phys. 1999;277:G219-G25.

37. Toogood JA, Barr AM, Stevens TK, Gati JS, Menon RS, Martin RE. Discrete functional contributions of cerebral cortical foci in voluntary swallowing: a functional magnetic resonance imaging (fMRI) "Go, No-Go" study. Exp Brain Res. 2005;161:81-90

38. Suzuki M, Asada Y, Ito J, Hayashi K, Inoue H, Kitano H. Activation of cerebellum and basal ganglia on volitional swallowing detected by functional magnetic resonance imaging. Dysphagia. 2003:18:71-7.

39. Car A, Jean A, Roman C. A pontine primary relay for ascending projections of the superior laryngeal nerve. Exp Brain Res. 1975:22(2):197-210.

40. Mosier K, Bereznaya I. Parallel cortical networks for volitional control of swallowing in humans. Exp Brain Res. 2001;140:280-9.

41. Zald DH, Pardo JV. The functional neuroanatomy of voluntary swallowing. Ann Neurol. 1999;46:281-6.

\section{Publisher's Note}

Springer Nature remains neutral with regard to jurisdictional claims in published maps and institutional affiliations.

\section{Submit your manuscript to a SpringerOpen ${ }^{\circ}$ journal and benefit from:}

- Convenient online submission

- Rigorous peer review

- Open access: articles freely available online

- High visibility within the field

- Retaining the copyright to your article

Submit your next manuscript at $>$ springeropen.com 